\title{
DESIGN OPTIMIZATION OF A CIVIL STRUCTURE USING NUMERICAL SIMULATIONS
}

\author{
Florian Vlădulescu ${ }^{\text {a, b,* }}$ \\ ${ }^{a}$ Doctoral School of Industrial Engineering and Robotics, University POLITEHNICA of Bucharest, Splaiul \\ Independenţei no. 313, 060042 Bucharest, Romania \\ ${ }^{\mathrm{b}}$ INAS S.A., Nicolae Romanescu Bld. no. 37C, 200738 Craiova, Romania \\ * Corresponding author: florianvladulescu@yahoo.com
}

\begin{abstract}
This optimization study aims to determine the effect of each input parameter on the output parameters, how the input parameters can interact with each other and also it is emphasized the determination of the values for the input parameters that optimize the responses. In this study, the objective is to obtain an optimal configuration for a resistance structure specific to a telecommunications tower. For this purpose, a variable geometric model using design parameters is created, based on which a 3D finite element model (FEM) is obtained, which is used in the optimization study. The FE model is updated automatically for each version of geometric model and is made using beam and shell elements. Design of Experiments (DOE) methodology allows for using a mathematical model that predicts how input parameters interact to create output responses in an optimization process. Parameters' correlation and monitoring allow for identifying important parameters and the correlation matrix and sensitivity graphs also help understanding the parametric relationships. Variation limits for design parameters are defined and these parameters can have integer or fractional values.
\end{abstract}

Keywords: civil structure, finite element analysis, parameters, optimization process

\section{INTRODUCTION}

The communication industry has seen a big increase nowadays and this is why many towers are used to increase the coverage area and network performance. In wireless domain, these towers play a very important role, hence, failure of such structure is a major concern. Thus, a major importance should be given in considering extreme conditions in the optimization process specific to this type of metallic structure. In this study, a four legged lattice tower is analyzed and optimized to static and seismic loads.

An optimization process, which uses the finite element method, help to obtain the best design for a structure using less resources and that will save a lot of money and human efforts.

In such an optimization process, values of the output parameters (deformation, stress etc.) are determined, depending on the input parameters initially established. Software applications based on the finite element method have modules dedicated to optimization studies that, for a preliminary analysis of a structure, allow for determining independent parameters, consequence of solving an optimization model, which implies the minimization or maximization of objective functions, while restrictions of other dependent parameters are imposed.

\section{PROBLEM DESCRIPTION}

To perform the constructive optimization study for a structure of a metal communications tower, which is fixed at the base, free at the top end and it is subjected to gravity, wind loads and seismic loads, the following categories of optimization parameters and restrictions are considered:

- fixed dimensions: B, T, H, S1, S2, S3, S4 (Fig. 1),

- input parameters: D1, D2, D3, L1. The first three parameters (D1, D2, D3) represent the outer diameters of the circular tube sections; the inner diameters of the circular tube sections change simultaneously with the outer ones and the section thicknesses remain constant; the parameter L1 is the side length of "L" section (Fig. 2),

- the diameter of the columns decreases with the height and, for this reason, two diameters D1 and D2 are defined, 
- D3 is the diameter of the frames that border the shells; the shells have constant thickness,

- main input parameters (working parameters) are D1 and L1; the other two input parameters (D2 and

D3) are defined according to parameter D1, so that, when D1 changes its value automatically and the other two input parameters change according to the expressions of dependency, - output parameters: $\sigma_{e c h}$ (equivalent von Mises stress), $U_{\text {total }}$ (total deformation),

- optimization restrictions: $L 1_{\text {min }}<L 1<L 1_{\text {max }}$, $D 1_{\min }<D 1<D 1_{\max }, \sigma_{\text {ech }} \leq \sigma_{a}$ (allowable maximum stress), $U_{\text {total }} \leq U_{a}$ (allowable maximum total deformation),

\section{OBJECTIVES}

This study presents, using the finite element method, the procedure for performing a dimensional optimization study for a given structure as above, having as objective function the minimization of mass.

The following dimensions are used in the preliminary finite element analysis:

- fixed dimension: $\mathrm{B}=4 \mathrm{~m}, \mathrm{~T}=1.2 \mathrm{~m}, \mathrm{H}=30 \mathrm{~m}$, $\mathrm{S} 1=6 \mathrm{~m}, \mathrm{~S} 2=4.5 \mathrm{~m}, \mathrm{~S} 3=6.5 \mathrm{~m}, \mathrm{~S} 4=7 \mathrm{~m}$; shells thickness $=20 \mathrm{~mm}$,

- variable dimensions (input parameters): D1 = 120 $\mathrm{mm}, \mathrm{D} 2=110 \mathrm{~mm}, \mathrm{D} 3=100 \mathrm{~mm}, \mathrm{~L} 1=75 \mathrm{~mm}$.

- objective function: mass minimization.

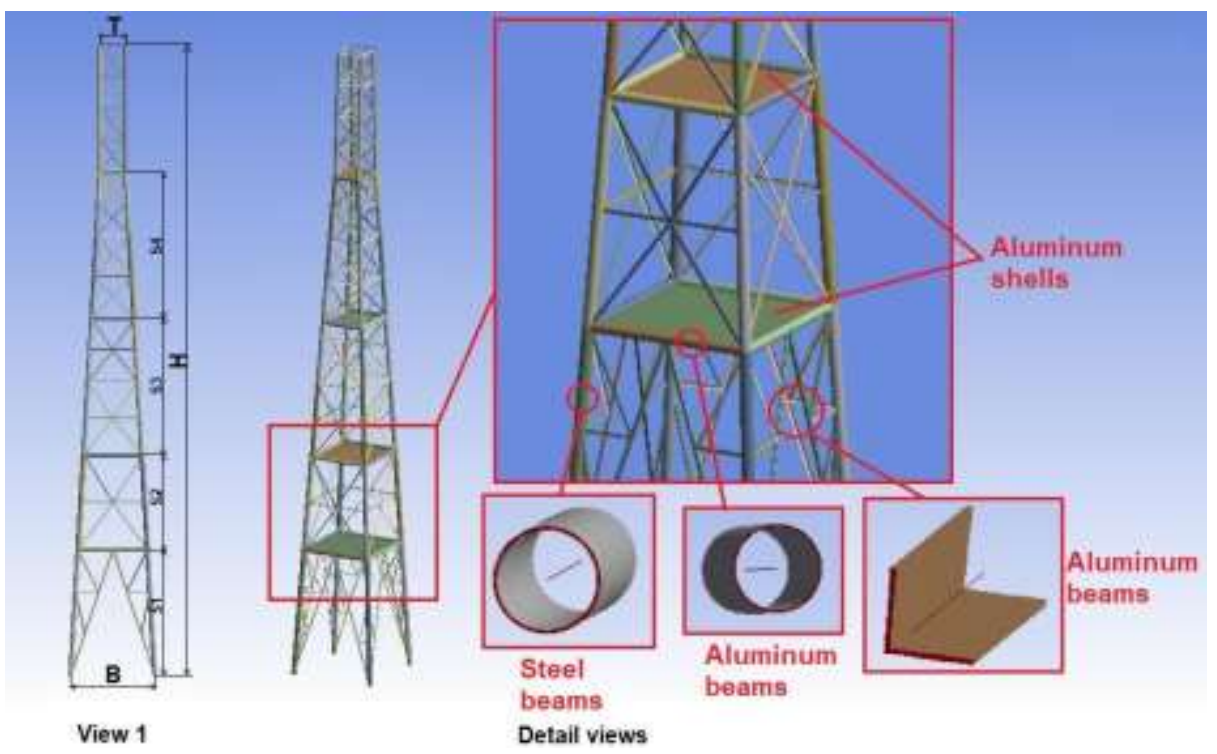

Fig. 1. The fixed dimensions of the structure in view 1

and the variable elements of the structure in detail views

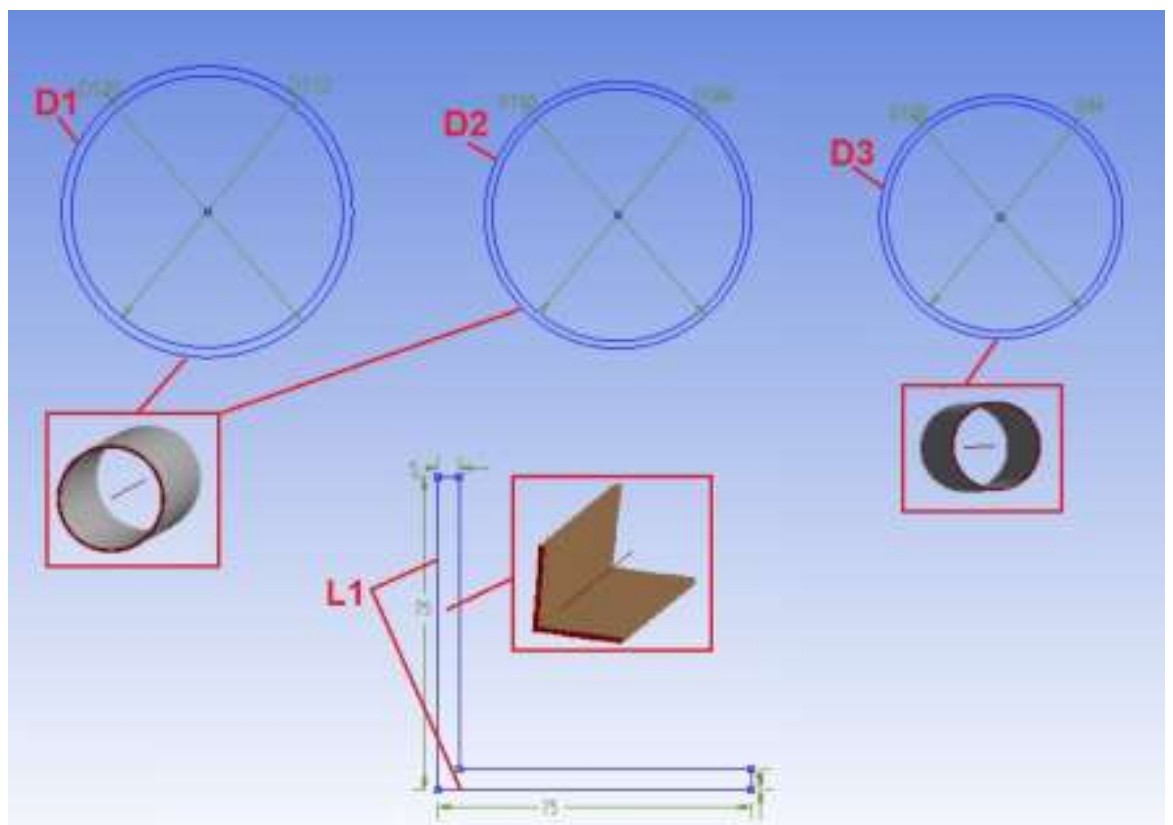

Fig. 2. Input parameters of the structure 


\section{MATERIALS}

The material used for the four columns is steel:

- longitudinal modulus of elasticity (Young's modulus): $\mathrm{E}=210000 \mathrm{~N} / \mathrm{mm}^{2}$,

- coefficient of transverse contraction (Poisson's coefficient): $\vartheta=0.3$,

- density: $\rho=7850 \mathrm{Kg} / \mathrm{m}^{3}$,

- ambient temperature: $T=22^{\circ} \mathrm{C}$,

- linear behavior.

The material used for all the other components of the tower (frames arranged horizontally and diagonally, shells) is aluminum alloy:

- longitudinal modulus of elasticity (Young's modulus): $\mathrm{E}=71000 \mathrm{~N} / \mathrm{mm}^{2}$,

- coefficient of transverse contraction (Poisson's coefficient): $\vartheta=0.33$,

- density: $\rho=2770 \mathrm{Kg} / \mathrm{m}^{3}$,

- ambient temperature: $T=22^{\circ} \mathrm{C}$,
- linear behavior.

\section{FINITE ELEMENT MODEL}

The geometry is not a complicated one, so a good quality finite element model is easily obtained:

- beam and shell element types of second order are used

- size of elements: $150 \mathrm{~mm}$

- total number of nodes: 15966

- total number of elements: 5492

\section{CALCULATION HYPOTHESES}

The proposed study is carried out in four stages: static structural analysis, modal analysis, response spectrum analysis and optimization. So, the study is based on a suite of three coupled analyzes, based on which the optimization process is performed (Fig. 4).

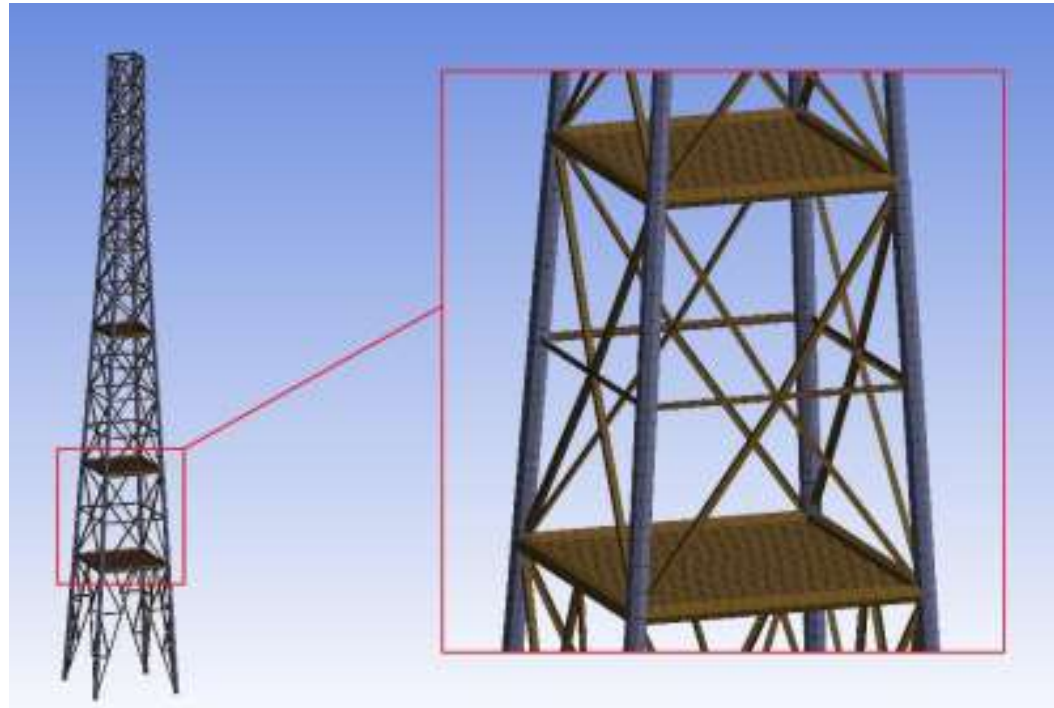

Fig. 3. Finite element model

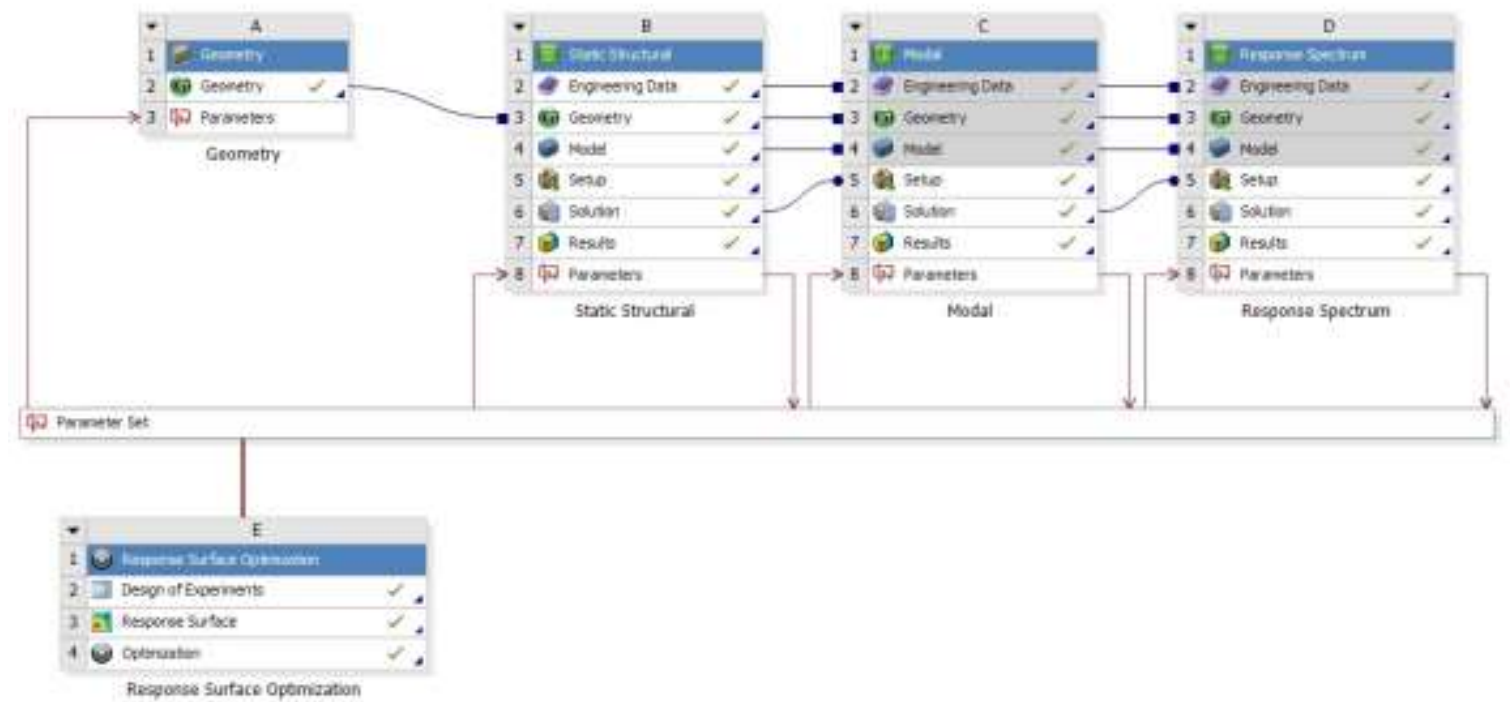

Fig. 4. Optimization study scheme 


\subsection{Static Structural Analysis}

In this study, the role of a static analysis is on the one hand to determine the behavior of the structure at static loads and, on the other hand, to obtain a prestressed structure, which is then studied at dynamic seismic demands.

In this static analysis, the structure is fixed at the base, free at the top end and is subjected to gravity and wind loads. The wind loads vary with height and are applied in the $\mathrm{X}$ direction, as shown in Fig. 4. Also the structure supports 20 antennas of $10 \mathrm{~kg}$ each disposed as in Figures 5 and 6.

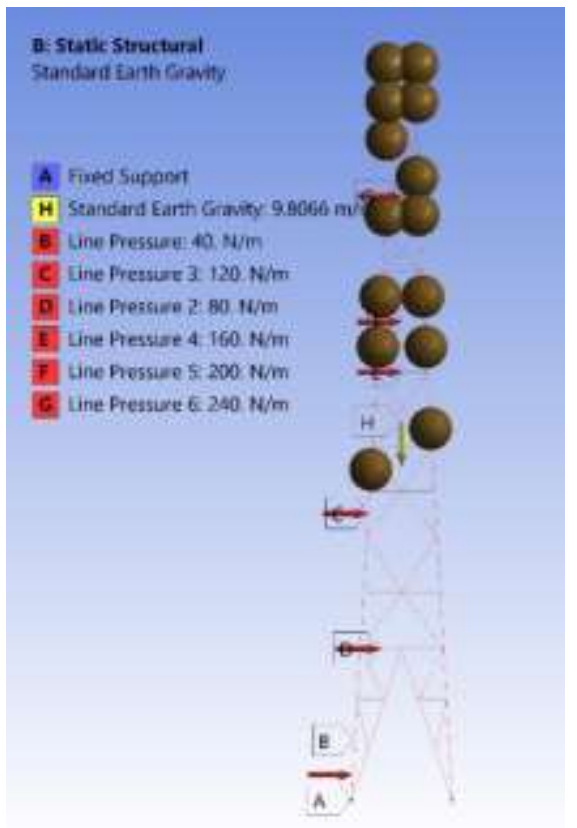

Fig. 5. Boundary conditions and loads

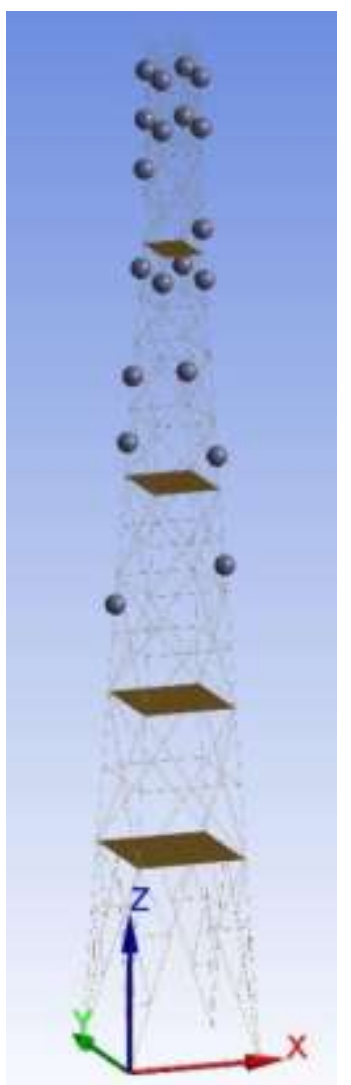

Fig. 6. Antennas arrangement

In the deformation process of the unoptimized structure model $(\mathrm{D} 1=120 \mathrm{~mm}, \mathrm{~L} 1=75 \mathrm{~mm})$, as a result of the gravity and wind loads actions to which are added the masses of the 20 antennas, there is observed:

- maximum total displacement of $42.09 \mathrm{~mm}$ (Fig. 7) at the top of the structure,

- maximum equivalent von Mises stress of 71.84 $\mathrm{MPa}$ (Fig. 8) at the bottom of the structure.

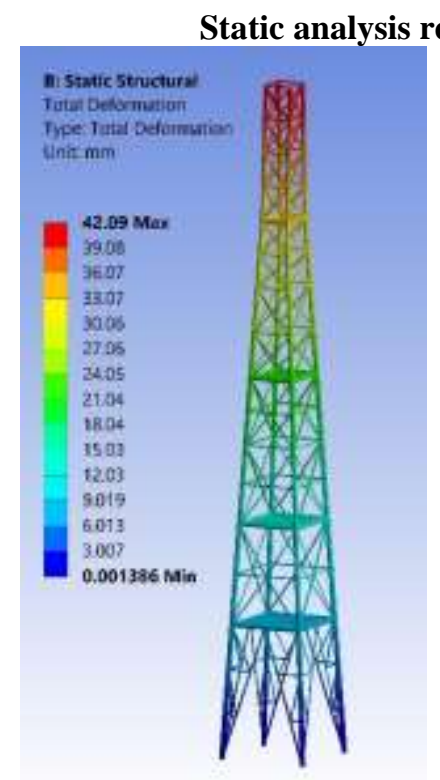

Fig. 7. Total deformation

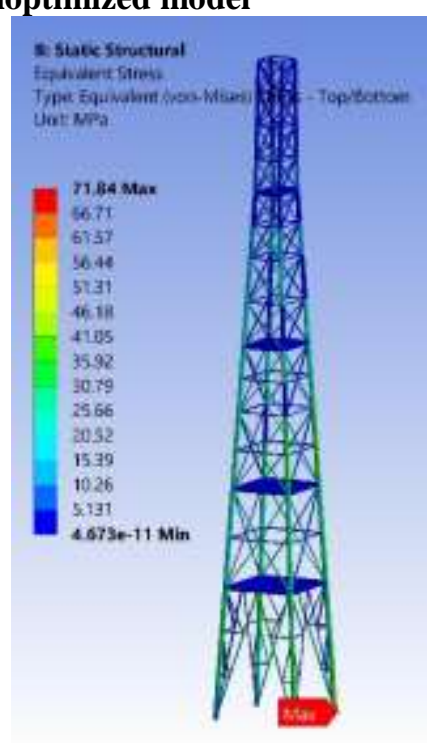

Fig. 8. Equivalentvon Mises stress 


\subsection{Modal Analysis}

A modal analysis determines the vibration characteristics (natural frequencies and mode shapes) of the structure. It can also serve as a starting point for a dynamic analysis, such as a response spectrum analysis, as is the case here. The natural frequencies and mode shapes are important parameters in the design of a structure for dynamic loading conditions.

In the modal analysis of the present study, the fixing conditions of the structure used in the static analysis are taken over, as well as all the output data from it. So, a modal analysis with pre-stress is performed.
The first 20 natural frequencies are extracted and then these frequencies are input data for spectrum analysis. Block Lanczos method was used to extract these frequencies.

The Block Lanczos method is especially powerful when searching for eigenfrequencies in a given part of the eigenvalue spectrum of a given system. The convergence rate of the eigenfrequencies will be about the same when extracting modes in the midrange and higher end of the spectrum as when extracting the lowest modes.

\begin{tabular}{|c|c|c|}
\hline & Mode & 1) Frequency $[\mathrm{Hz}]$ \\
\hline 1 & 1. & 40043 \\
\hline 2 & 2 & 2.7813 \\
\hline 3 & 3. & 5.6546 \\
\hline 4 & 4. & 73451 \\
\hline 5 & 5. & 7.9315 \\
\hline 6 & 6. & 14356 \\
\hline 7 & 7. & 1476 \\
\hline I & 8. & $157 \mathrm{JI}$ \\
\hline 9 & 9. & 17.538 \\
\hline 10 & 10. & 18.694 \\
\hline t1 & 11. & 20913 \\
\hline 12 & 12. & 21,371 \\
\hline 13 & 13. & 21.672 \\
\hline 14 & 14 & 22.248 \\
\hline 15 & 15. & 22366 \\
\hline 16 & 16. & 22589 \\
\hline 17 & 17. & 23085 \\
\hline 18 & 18. & 23219 \\
\hline 19 & 19. & 23559 \\
\hline 20 & 20. & 24015 \\
\hline
\end{tabular}

Table 1. The first 20 natural frequencies

\subsection{Response Spectrum Analysis}

Response spectrum analyses are widely used in civil structure designs, for example, high-rise buildings, nuclear power plants or high metallic structures under seismic loads. The results from a response spectrum analysis are deterministic maxima. For a given excitation, the maximum response is calculated based upon the input response spectrum and the method used to combine the modal responses. The combination methods used in this study is the Rosenblueth's Double Sum Combination (ROSE) because we have closely-spaced modes because the natural frequencies resulting from the modal analysis have closely-spaced values and in this case the ROSE method is recommended.

ROSE method is providing a means of evaluating modal correlation for the response spectrum analysis. Mathematically, the approach is built upon random vibration theory assuming a finite duration of white noise excitation. The ability to account for the modes coupling makes the response estimate from the ROSE method more realistic and closer to the exact time history solution.

The excitation is applied in the form of a response spectrum. The response spectrum can have
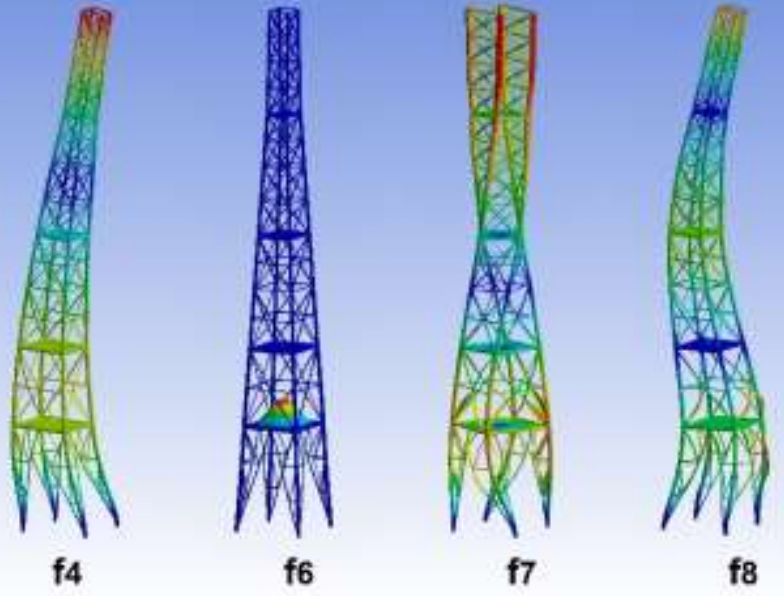

Fig. 9. Mode shapes

displacement, velocity or acceleration units. For each spectrum value, there is one corresponding frequency. Excitation must be applied at fixed degrees of freedom.

Response spectrum is calculated based on modal responses. A modal analysis is therefore a prerequisite.

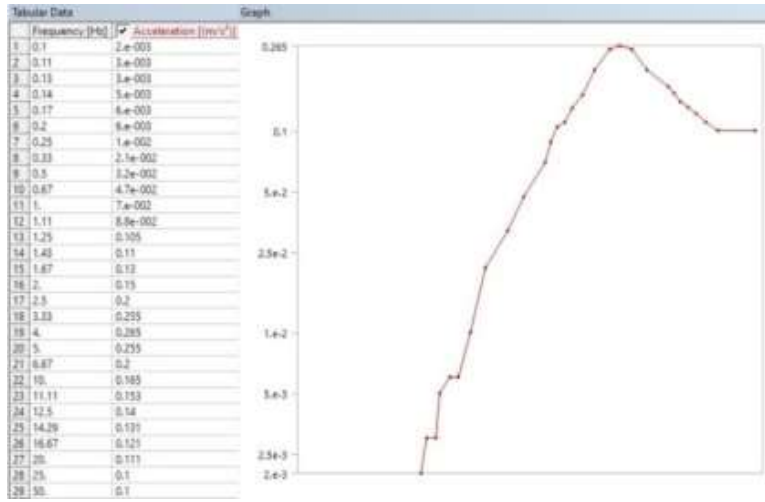

Fig. 10. Seismic excitation spectrum

The seismic excitation spectrum used is known as "Savannah river earthquake" and it is shown in figure 12. One input excitation spectrum is applied to all 
boundary condition types defined in the model in the $\mathrm{X}$ direction, so it is used "single point" spectrum type.

In the deformation process of the unoptimized structure model $(\mathrm{D} 1=120 \mathrm{~mm}, \mathrm{~L} 1=75 \mathrm{~mm})$ as a result of the seismic loads actions to which are added pretensioning from static analysis is observed:

- maximum total displacement of $24.3 \mathrm{~mm}$ (Fig.

11) at the top of the structure

- maximum equivalent von Mises stress of 45.7

$\mathrm{MPa}$ (Fig. 12) at the bottom of the structure.

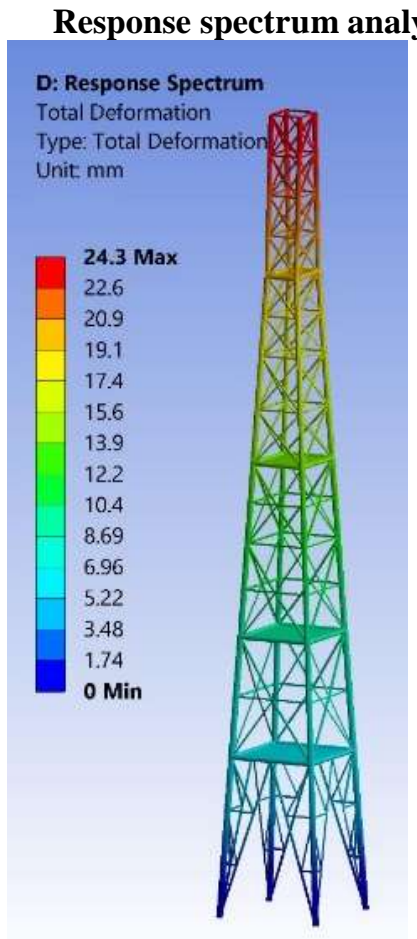

Fig. 11. Total deformation

\section{OPTIMIZATION PROCESS}

It can be observed that the values resulting from the analyzes are small and therefore the initial model can be can be modified and thus the mass of the structure can be greatly reduced.

The main data used in the optimization process are:

- input parameters: D1, L1,

- output parameters: $\sigma_{e c h}$ (equivalent von Mises stress), $U_{\text {total }}$ (total deformation),

- optimization restrictions: $L 1_{\min }<L 1<L 1_{\max }$, $D 1_{\text {min }}<D 1<D 1_{\max } \quad, \quad \sigma_{e c h} \leq \sigma_{a} \quad$ (allowable maximum stress), $\quad U_{\text {total }} \leq U_{a} \quad$ (allowable maximum total deformation),

- the limit values of the input parameters are: $D 1_{\min }=60 \mathrm{~mm}, D 1_{\max }=120 \mathrm{~mm}, L 1_{\min }=$ $50 \mathrm{~mm}, L 1_{\max }=75 \mathrm{~mm}$,

- the optimization restrictions are: allowable maximum stress $\sigma_{a}=150 \mathrm{MPa}$ and allowable maximum total deformation $U_{\text {total }}=100 \mathrm{~mm}$; these allowable values are available for both static structural analysis and earthquake analysis,

- objective function: mass minimization,

- design of Experiments (DOE) methods used: reduced factorial method and response surface method,

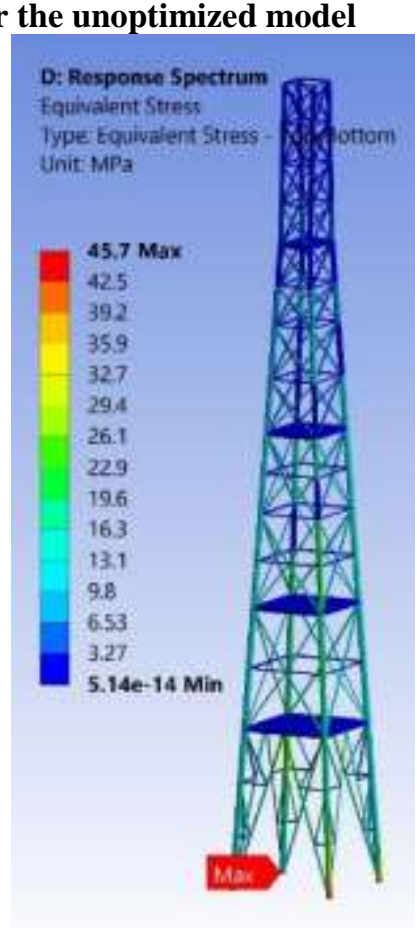

Fig. 12. Equivalent von Mises stress

- optimization solution algorithm: NLPQL (Nonlinear Programming by Quadratic Lagrangean), which is based on the gradient algorithm for models with only one objective function and several optimization restrictions.

The reduced factorial method can be mathematically modeled in several ways. In the present study was used a mathematical model known as "Central composite design".

"Central composite design" is a reduced factorial experiment of type $2^{k}$, in which additional experimental points are added to the $2^{k}$ experimental points: the central point of the experiment and $2 k$ points placed in "star" position at " $\alpha$ " distance (sometimes written "alpha" distance) compared to the central point, reaching the size of the $2^{k}+2 k+1$ selection. Because the experimental points are symmetrical to the central point of the experiment, it is called "central". There are situations where two or more experiments are needed in the central point and situations when one or two experiments in the center are sufficient. $n_{c}$ is the number of experiments in the center and the total number of experimental points $N$ for $k$ factors will be: $N=2^{k}+2 k+n_{c}$. The experiments at the central point provide information about the existence of the response surface curvature. If there is a curvature in the system, adding the experimental 
points placed in "star" position allows the efficient estimation of the purely quadratic terms. "Central composite design" is defined according to the criterion based on which the " $\alpha$ " distance is calculated, the most commonly encountered in practice being the central composite experiments orthogonal and rotatable of the second order. Because there are more selections than those strictly required for a bilinear interpolation $\left(2^{k}\right)$, the curvature of the experimental space can be estimated.

The response surface method (MSR) is a group of mathematical and statistical techniques that explores the relationship between the independent variables and the response variable, in order to optimize the desired response of the investigated system, to explore the optimal operating conditions. The term "response surface" is used to describe the surface that represents the response of a process or system when the values of the input parameters vary in the specified fields.

The first "step" for applying MSR is to determine an appropriate function that represents the relationship between the output response variable and the input variables, a function that is generally unknown. If the response of the examined system can be sufficiently modeled using a linear function of input variables, a so-called first degree model can be used. If the answer is more complex, it is used a second degree model (a quadratic function) or even a combination of the first degree model with the second degree model.

The parameters in the approximation models are correctly determined if an experiment is performed using an appropriate type of DOE. For many MSR studies, the central composite experiment is used, as is the case with the present study. As an alternative to the central composite experiment method, the BoxBehnken experiment can be chosen. The latter requires lower costs, but should only be used if the experiment's borders are assumed to be known.

Following the solution of the optimization analysis and in accordance with the restrictions specified above, it is observed that the optimal design variant corresponds to the values $\mathrm{D} 1=60 \mathrm{~mm}$ and L1=60 mm (Table 3).

\begin{tabular}{|c|c|c|c|c|c|c|c|}
\multicolumn{1}{|c|}{ Table 2. Design of experiments } \\
Design & $\begin{array}{c}D 1 \\
{[\mathrm{~mm}]}\end{array}$ & $\begin{array}{c}L 1 \\
{[\mathrm{~mm}]}\end{array}$ & $\begin{array}{c}\text { Total mass } \\
{[\mathrm{kg}]}\end{array}$ & $\begin{array}{c}\text { Maximum } \\
\text { equivalent } \\
\text { von Mises stress } \\
{[\mathrm{MPa}]} \\
\text { (static loads) }\end{array}$ & $\begin{array}{c}\text { Maximum } \\
\text { equivalent } \\
\text { von Mises stress } \\
{[\mathrm{MPa}]} \\
\text { (seismic loads) }\end{array}$ & $\begin{array}{c}\text { Total } \\
\text { deformation } \\
{[\mathrm{mm}]} \\
\text { (static loads) }\end{array}$ & $\begin{array}{c}\text { Total } \\
\text { deformation } \\
{[\mathrm{mm}]} \\
\text { (seismic loads) }\end{array}$ \\
\hline 1 & 90 & 62.5 & 5825.4 & 94.89 & 102.42 & 56.82 & 25.68 \\
\hline 2 & 60 & 62.5 & 4509.3 & 119.16 & 131.52 & 85.37 & 26.58 \\
\hline 3 & 120 & 62.5 & 7141.5 & 76.18 & 79.52 & 43.17 & 24.65 \\
\hline 4 & 90 & 50 & 5673.1 & 129.17 & 302.46 & 58.86 & 89.76 \\
\hline 5 & 90 & 75 & 5977.6 & 87.99 & 68.65 & 55.49 & 24.78 \\
\hline 6 & 60 & 50 & 4357.0 & 252.37 & 684.37 & 88.23 & 121.64 \\
\hline 7 & 120 & 50 & 6989.3 & 148.97 & 497.52 & 44.94 & 79.77 \\
\hline 8 & 60 & 75 & 4661.5 & 113.04 & 125.27 & 83.65 & 25.83 \\
\hline 9 & 120 & 75 & 7293.7 & 71.84 & 45.70 & 42.08 & 24.30 \\
\hline
\end{tabular}

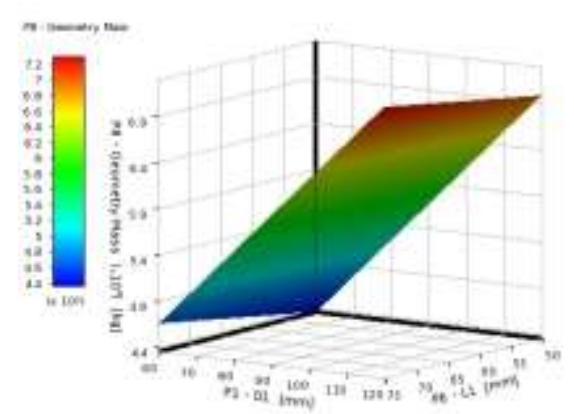

Mass variation according to the values of the two input parameters (D1 and L1)

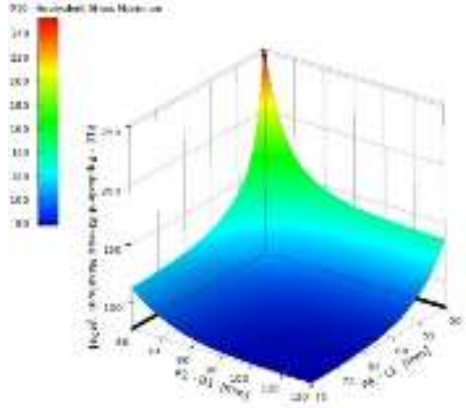

Variation of the maximum equivalent von Mises stress according to the values of the two input parameters (D1 and

L1) due to static loads

Fig. 13. Response surfaces

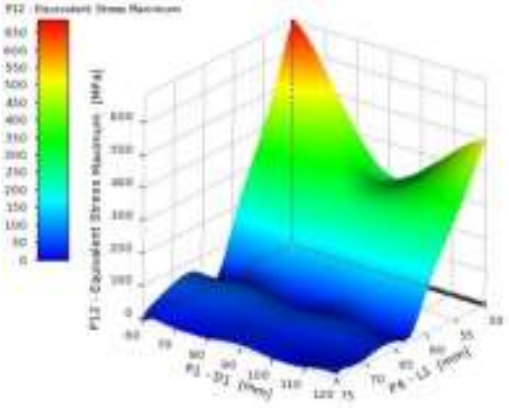

Variation of the maximum equivalent von Mises stress according to the values of the two input parameters (D1 and L1) due to seismic loads 
Table 3. Optimization results

\begin{tabular}{|c|c|c|c|c|}
\hline \multicolumn{2}{|c|}{ Optimization objective and parameters } & $\begin{array}{c}\text { Candidate } \\
\text { design 1 }\end{array}$ & $\begin{array}{c}\text { Candidate } \\
\text { design 2 }\end{array}$ & $\begin{array}{c}\text { Candidate } \\
\text { design 3 }\end{array}$ \\
\hline \multirow{2}{*}{ Objective } & Total mass [kg] & 4477.80 & 4620.10 & 5825.40 \\
\hline \multirow{4}{*}{ parameters } & $D 1[\mathrm{~mm}]$ & 60 & 62.89 & 90 \\
\cline { 2 - 5 } & L1 [mm] & 59.91 & 61.19 & 62.50 \\
\hline \multirow{4}{*}{$\begin{array}{c}\text { Output } \\
\text { parameters }\end{array}$} & $\begin{array}{c}\text { Maximum equivalent } \\
\text { von Mises stress [MPa] } \\
\text { (static loads) }\end{array}$ & 134.20 & 114.67 & 94.89 \\
\cline { 2 - 5 } & $\begin{array}{c}\text { Maximum equivalent } \\
\text { von Mises stress [MPa] } \\
\text { (seismic loads) }\end{array}$ & 148 & 125.28 & 102.42 \\
\cline { 2 - 5 } & $\begin{array}{c}\text { Total deformation [mm] } \\
\text { (static loads) }\end{array}$ & 87.12 & 76.12 & 56.82 \\
\cline { 2 - 5 } & $\begin{array}{c}\text { Total deformation [mm] } \\
\text { (seismic loads) }\end{array}$ & 27.34 & 26.52 & 25.68 \\
\hline
\end{tabular}

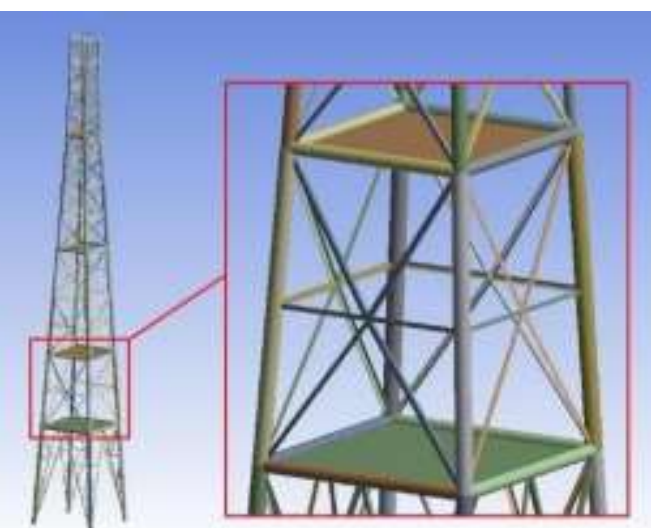

Fig. 14. Initial structure model

The results show that the mass of the structure resulting from the optimization process is reduced to $4477.8 \mathrm{Kg}$ (initially having the value of $7293.7 \mathrm{~kg}$ ). Also, the geometric aspect specific to the two structure models (initially and optimized) is greatly modified (Figures 14 and 15).

The values corresponding to the maximum equivalent von Mises stress (124.13 MPa) due to static loads, respectively maximum equivalent von Mises stress (150 MPa) due to seismic loads and also the values corresponding to the maximum total deformation for both cases obtained for the optimized model does not endanger the integrity of the structure. The authors could say that the mass of the structure could be reduced if we increased the maximum allowable value of the equivalent von Mises stress and total deformation imposed as an optimization constraints.

If other optimization restrictions are desired then the configuration of the optimization analysis must be modified and in some cases the input and output parameters and the objective function must be restored.

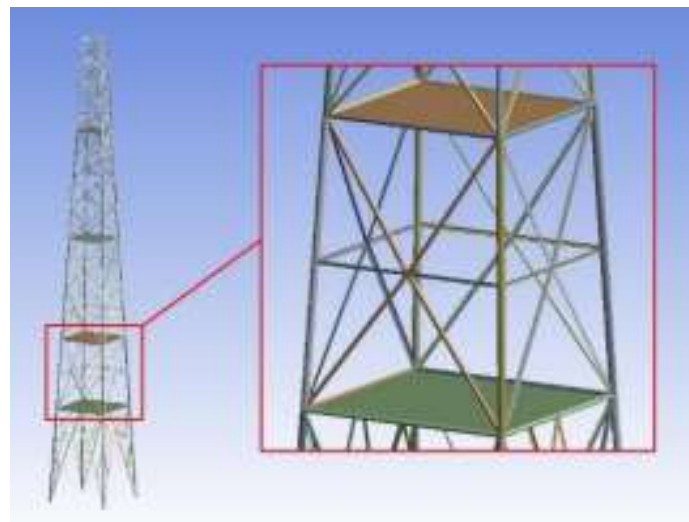

Fig. 15. Optimized structure model

\section{CONCLUSIONS}

In this paper, some of the most important aspects of using the finite element method in mechanical engineering were presented, emphasizing its applicability in the process of optimizing the structural components.

In the development phase of the calculation model for optimization, the practical aspects that are often difficult to formulate in numerical terms must also be considered. Finding a solution is done by the design engineer or by other members of the technical team based on intuition and experience gained over time.

Optimization techniques have become increasingly popular as very useful design tools for achieving lightweight, durable and low cost structures. Many of these optimization techniques are based on the finite element method and the use of increasingly efficient computers. This is because, in general, optimization studies involve many experiments and also the level of refinement of the finite element model often requires the use of a high performance computer. 
Also, for efficient modeling it is recommended to use some types of finite elements that must first be analyzed both theoretically and practically, so that their performances can be known and whether or not they match the design used in optimization study. The use of shape functions, numerical integration as well as the calculation of displacements and stresses are also important.

This optimization study was accomplished by going through the main stages of a finite element optimization analysis, in which the emphasis is placed on the modeling and analysis of a structure of communications tower which is then dimensional optimized.

The considered optimization model involves the use of two geometric parameters as input variables, four output parameters limited below the allowable values imposed as an optimization constraints and an objective function that consists in minimizing the structure mass.

After the optimization analysis was solved, a considerable reduction of the structure mass was obtained under the conditions where the maximum equivalent von Mises stress and total deformation increased, but did not exceed the allowable values.

\section{ACKNOWLEDGEMENTS}

The work of Florian Vlădulescu was supported by the project ANTREPRENORDOC, in the framework of Human Resources Development Operational Programme 2014-2020, financed from the European Social Fund under the contract 36355/23.05.2019 HRD OP /380/6/13 - SMIS Code: 123847.

\section{REFERENCES}

[1] Radeș M. (2006) Analiza cu elemente finite, UPB, Bucureşti.
[2] Constantinescu I.N., Picu C.R., Hadăr A., Gheorghiu H. (2006) Rezistenţa materialelor pentru ingineria mecanică, Editura BREN, Bucharest

[3] Eschenauer H., Koski J., Osyczka A. (1990) Multicriteria Design Optimization, Springer-Verlag, Berlin, Germany.

[4] Cicală E.F. (2005) Metoda experimentelor factoriale. Proiectarea experimentelor, modelare, optimizare. Colecția „Prelucrarea datelor”, Editura Politehnica, Timișoara.

[5] Myers R.H., Montgomery D.C. (2002) Response Surface Methodology: process and product optimization using designed experiments, 2nd ed., John Wiley \& Sons Inc., New York (USA).

[6] G. E. P. Box, K. B. Wilson, On the experimental attainment of optimum conditions, Journal of the Royal Statistical Society Series B 13, 1951.

[7] Box G.E.P., Behnken D. (1960) Some new three level designs for the study of quantitative variables, Technometrics 2.

[8] Cox R.D., Reid N. (2000)The theory of the design of experiments, Boca Raton: Chapman\& Hall/CRC.

[9] Eschenauer H., Koski J., Osyczka A. (1990) Multicriteria design optimization, Berlin: SpringerVerlag.

[10] Lanczos C. (1950) An iteration method for the solution of the eigenvalue problem of linear differential and integral operators, Journal of Research of the National Bureau of Standards 45(4), pp. 255-282.

[11] Rosenblueth E., Elorduy J. (1969) Responses of linear systems to certain transient disturbances, Proceedings of the $4^{\text {th }}$ World Conference on Earthquake Engineering.

[12] *** ANSYS Design Modeler User's Guide, ANSYS Inc., Canonsburg (USA), 2019 R3

[13] *** ANSYS Mechanical User's Guide, ANSYS Inc., Canonsburg (USA), 2019 R3.

[14] *** ANSYS DesignXplorer User's Guide, ANSYS Inc., Canonsburg (USA), 2019 R3. 